\title{
Hubungan antara gaya mengajar guru dan efikasi diri dengan kedisiplinan siswa SMA di Kota Jayapura
}

\author{
Margaretha Pigay ${ }^{1 *}$, Yansen Alberth Reba ${ }^{2}$ \\ Fakultas Keguruan dan IImu Pendidikan, Universitas Cenderawasih ${ }^{12}$ \\ *) Alamat korespondensi: Jl. Raya Sentani, Jayapura, 99351, Indonesia : E-mail: margarethapigay98@gmail.com
}

\begin{abstract}
Article History: Received: 03/03/2021;

Revised: 21/06/2021;

Accepted: $27 / 06 / 2021$

Published: 30/06/2021
\end{abstract}

How to cite:

Pigay, M. \& Reba, Y.A. (2021).

Hubungan antara gaya mengajar guru dan efikasi diri dengan kedisiplinan siswa SMA di Kota Jayapura. Teraputik: Jurnal Bimbingan dan Konseling, 5(1), pp. 24-29. DOI:

10.26539/teraputik.51590

\begin{abstract}
Abstrak: Penelitian ini bertujuan untuk mengetahui ada atau tidaknya hubungan antara gaya mengajar guru dan efikasi diri dengan kedisiplinan peserta didik SMA YPPK Taruna Dharma Kota Jayapura. Metode yang digunakan adalah metode penelitian kuantitatif. Populasi penelitian berjumlah 203 peserta didik, dengan sampel penelitian 34 yang ditentukan dengan teknik Proportionate Statified Random Sampling. Hasil dari penelitian yaitu adanya hubungan antara gaya mengajar guru dan efikasi diri dengan kedisiplinan peserta didik SMA YPPK Taruna Dharma Kota Jayapura. Efikasi diri dan gaya mengajar guru secara simultan atau bersama-sama berpengaruh terhadap variabel kedisiplinan diri sebesar $82,2 \%$, sisanya $17,8 \%$ dipengaruhi oleh faktor-faktor lain. Efikasi Diri dan Gaya Mengajar Guru secara simultan atau bersama-sama berpengaruh terhadap variabel Kedisiplinan Diri sebesar 82,2\%, sisanya sebesar 17,8\%
\end{abstract} dipengaruhi oleh faktor-faktor lain.

Kata Kunci: Gaya Mengajar, Efikasi Diri, Kedisiplinan, Siswa

Abstract: This study aims to find out whether there is a relationship between teaching style of teachers and self-efficacy with disciplinary behavior of students of SMA YPPK Taruna Dharma, Jayapura. It utilized quantitative research method. The population of this study involved 203 students with a total sample of 34 students determined using proportionate stratified random sampling. The results of this study indicated that there was a relationship between teaching style of teachers and self-efficacy with disciplinary behavior of students of SMA YPPK Taruna Dharma, Jayapura. Self-efficacy and teaching style of teachers simultaneously had an effect on disciplinary behavior variable of the students by $82.2 \%$, while the other $17.8 \%$ was influenced by other factors.

Keywords: Teaching Style, Self-Efficacy, Disciplinary, Students distributed under the Creative Commonted under the Creative Commons 4.0 Attribution License, which permits unrestricted use, distribution, and reproduction in any medium, provided the original work is properly cited. (C) 2021, Pigay, M. \& Reba, Y.A. (s).

\section{Pendahuluan}

Pendidikan atau pengajaran adalah sarana dan prasarana penting untuk membentuk pribadi manusia, salah satu tujuannya adalah membebaskan manusia dari buta aksara. Hal ini menandakan betapa pentingnya pendidikan bagi setiap individu. Pembentukan pribadi manusia yang beradab dimulai dari pendidikan didalam keluarga dan berlanjut ke pendidikan di sekolah. Pendidikan di sekolah bertujuan untuk menyempurkan kepribadian manusia yang telah ditanamkan dalam keluarga. Upaya pembentukan kepribadian manusia di sekolah dilaksanakan dengan sebuah sistem pendidikan nasional. Sistem pendidikan nasional tercantum pada UUD RI Nomor. 20 Tahun 2003, Pasal 1 Ayat 1 menjelaskan jika pendidikan merupakan upaya nyata dan sistematik untuk mewujudkan keadaan bersekolah serta sistem studi supaya siswa dapat mengembangkan kemampuannya, seperti menguasai spirit mental, keyakinan, penguasaan diri, watak, moral, dan kualitas atau keahlian yang dapat memajukan dirinya dan lingkungan sekitarnya. Guna terwujudnya sistem pengetahuan nasional yang secara menyeluruh dapat diterapkan, maka dibutuhkan suatu pedoman pembelajaran efektif di sekolah untuk menyelamatkan siswa yang terbimbing dan terlatih (Cahyani \& Winata, 2020).

Kedisiplinan merupakan suatu proses ketaatan peserta didik dalam meningkatkan minat belajar terhadap pembentukan efikasi diri untuk mencapai prestasi yang memuaskan. Untuk 
pendidikan, efikasi merupakan cara mendasar yang berupaya untuk memajukan suatu kedisiplinan bagi peserta didik, adalah mengajak para siswa dan siswi dapat membangkitkan rasa keyakinan diri yang besar dengan pandangan hidup yang kokoh untuk memajukan kedisiplinan dalam diri (Elly, 2016). Kedisiplinan pun mampu mengembangkan cara belajar peserta didik agar lebih kompeten dalam meningkatkan minat. Upaya yang dilakukan agar peserta didik berinteraksi dengan baik, yaitu menggunakan gaya mengajar guru yang mampu mengambil pandangan atau kefokusan dari peserta didik (Nadhifa et al., 2020).

Gaya mengajar guru atau cara mendidik merupakan suatu hal yang sangat utama dalam mengembangkan potensi belajar peserta didik (AI Khumaero \& Arief, 2017). Dalam UUD Nomor. 14 Tahun 2005 Pasal 1 Ayat 1 mengenai dosen dan guru: yaitu Bab 1 Pasal 1, Ayat 1 menjelaskan jika guru atau pendidik merupakan bagian yang terpenting bagi peserta didik di sekolah yang mampu mengarahkan, menuntun, mendidik, dan melatih peserta didik agar meningkatkan prestasi yang berkompeten. Dalam mengembangkan pendidikan di Indonesia Guru harus memiliki kemampuan mendasar yang baik dan berkompeten. Salah satu kemampuan mendasar tersebut adalah mampu menguasai klasifikasi pendidikan tertentu, seperti berkompeten bersosial, berkompeten berkatrakter, karakter pedagogik, serta berkompeten berpengalaman melalui sekolah profesi. Pengajar atau guru diibaratkan sebagai pelita di kegelapan: menerangi peserta didik agar dapat meraih cita-cita mereka di masa mendatang. Sebagai guru yang profesional, maka ia mampu memberikan sesuatu kepada peserta didik yang menarik perhatian mereka, baik ketika proses pembelajaran berlangsung maupun aktivitas di luar ruang belajar atau kelas agar pendidikan tetap berlangsung sebaik mungkin. Pendidikan mencapai keberhasilan jika peserta didik dapat meningkatkan minat belajar mereka melalui pengembangan minat peserta didik sehingga membentuk cara belajar yang efektif (Djamarah \& Zain, 2010). Cara belajar paserta didik dapat dilihat dari hasil belajar maupun keaktifan dalam kelas, meliputi ujian harian, tugas rumah maupun ujian akhir semester di sekolah. Dalam mengembangkan pendidikan yang optimal, guru harus bisa memahami serta memercayai kepada peserta didik supaya tata cara belajar mengajar berlangsung dengan efektif (Widiyaningtyas \& Muhyadi, 2018).

Efikasi diri merupakan suatu keteguhan mengenai kecakapan diri peserta didik dalam pengembangan semangat, intelektual, langkah-langkah yang menentukan perkembangan masa depannya. Efikasi diri merupakan keteguhan peserta didik mengenai keteguhannya untuk menjalankan tanggung jawab sebagai peserta didik demi menggapai cita-cita (Adestyani et al., 2020). Untuk memahami perkembangan diri, peserta didik perlu menggunakan tiga cara, yaitu strength (kekuatan), generality (generalitas), dan persuasi verbal. Efikasi diri mampu mengoptimalkan kemandirian dari peserta didik ketika berada saat didalam kelas dan ketika diluar kelas saat memiliki tujuan untuk menggapai impiannya. Untuk yang memiliki keyakinan yang baik dan besar dalam diriakan lebih baik ketika menggapai prestasi. Kebalikannya, peserta didik yang kurang efikasi diri prestasi yang digapai pun sangat kurang.

Sehingga, dari pengamatan yang diperoleh penulis, ketika melakukan program pengalaman lapangan (PPL) di SMA YPPK Taruna Dharma Kota Jayapura, menujukan bahwa peserta didik kurang disiplin yang ditujukan oleh : a). membolos dari mata pelajar; b). alasan izin ke toilet demi menghindar dari mata pelajaran; c). alasan sakit di ruang UKS; dan d) jarang kerjakan tugas mata pelajaran; e) sering tidak masuk sekolah; f) sering terlambat sekolah. Kurangnya kedisiplinan peserta didik terlebih khusus karena kurangnya efikasi diri dan gaya mengajar guru.

\section{Metode}

Jenis penelitian yang dipakai oleh peneliti ini merupakan penelitian deskriptif kuantitatif yang berbentuk korelasional dan tergolong ke dalam riset expost facto. Populasi pada riset ini merupakan Keseluruhan peserta didik kelas XI, SMA YPPK Taruna Dharma Kota Jayapura, yang berjumlah 203 peserta didik. Peneliti mengambil sampel di satu kelas saja dari populasi kelas XI yaitu kelas XI IPA 2 yang berjumlah 34 peserta didik. Sampel untuk riset ini dikumpulkan memakai teknik Proporsionate Stratified Random Sampling. Teknik pengumpulan 
data yang dipakai dalam penelitian merupakan kuesioner jenis skala. Poin - poin dalam skala sudut disediakan jawaban dengan kategori skala ketidak sesuaian dan skala kesesuaian terhadap poin pertanyaan. Terdapat 4 pilihan jawaban yakni sangat tidak setuju, tidak setuju, setuju, dan sangat setuju. Teknik analisis data dalam riset ini menggunaka program SPSS 20 $J r>r$ windouws, sebelumnya harus memenuhi syarat. Analisis data di dalam riset ini akan memakai statistic parametrik. Data yang akan di analisis harus merupakan data interval atau ratio, maka dari itu data di dalam riset ini akan diubah manjadi data interval lebih dulu. Yang pertama, data yang akan di analisa harus berdistribusi normal, lalu untuk pelaksanaan tes regresi harus memenuhi hipotesis linieritas. Analisis data terdiri dari 1) Analisis Prasyarat (Uji Normalitas dan Uji Linearitas), 2) Uji Hipotesis.

\section{Hasil dan Diskusi}

Hasil penelitian hubungan antara Gaya mengajar guru dan efikasi diri dengan kedisiplinan peserta didik di SMA YPPK Taruna Dharma Kota Jayapura pertama-tama menunjukkan koefisien determinasi Model Summary. Koefisien determinasi $\left(R^{2}\right)$ merupakan sebuah perhitungan (nilai skala) guna menaksir berapa besarnya keunggulan variabel-variabel independen yang digunakan dalam perbandingan regresi, dengan tujuan menginterpretasikan ragam variabel dependen (Sugiyono, 2010). Nilai koefisien determinasi berkisar antara 0 dan 1. Nilai koefsien determinasi $R^{2}$ yang rendah (yang mengarah pada angka nol), yakni bahwasannya keunggulan variabel-variabel dependen secara bersamaan mendeskripsikan ragam variabel independen yang terbatas. Nilai koefisien determinasi $R^{2}$ yang mengarah pada angka satu berarti variabel-variabel independen dapat memberikan kontribusi yang hampir menyeluruh sesuai dengan seberapa besar data yang diperlukan guna memprediksi beragam variasi pada variabel independen.

Tabel 1. Koefisien Determinasi Model Summary

\begin{tabular}{lllll}
\hline Model & $\mathrm{R}$ & R Square & Adjusted R Square & Std. $\begin{array}{c}\text { Error of } \\
\text { Estimate }\end{array}$ \\
\hline 1 & $.906^{\mathrm{a}}$ & .822 & .750 & 8.88775 \\
\hline
\end{tabular}

a. Predictors: (Constant), Efikasi Diri, Gaya Mengajar Guru

Berdasarkan Tabel 1, nilai koefisien determinasi $R^{2}$ terletak pada kolom $R$-Square. Diketahui nilai koefisien determinasi sebesar $R^{2}=0,822$. Nilai tersebut berarti Efikasi Diri dan Gaya Mengajar Guru secara simultan atau bersama-sama berpengaruh terhadap variabel Kedisiplinan Diri sebesar $82,2 \%$, sisanya sebesar $17,8 \%$ dipengaruhi oleh faktor-faktor lain.

Tabel 2. Uji Hipotesis

\begin{tabular}{lllllll}
\hline Model & & Sum of Squares & Df & Mean Square & $F$ & Sig. \\
\hline 1 & Regression & 835.510 & 2 & 417.755 & 5.289 & $.011^{\text {a }}$ \\
\cline { 2 - 7 } & Residual & 2448.755 & 31 & 78.992 & & \\
\cline { 2 - 6 } & Total & 3284.265 & 33 & & & \\
\hline
\end{tabular}

a. Predictors: (Constant), Efikasi Diri, Gaya Mengajar Guru

b. Dependent Variable: Kedisiplinan Diri

Cara pengambilan keputusan terhadap hipotesis dapat dilakukan dengan membandingkan nilai signifikansi $F$ hitung dengan taraf signifikansi penelitian yaitu 0,05 . Jika nilai signifikansi $F$ hitung $<0,05$ maka hal ini berarti pengaruh antara variabel bebas secara keseluruhan terhadap variabel terikat signifikan secara statistik. Namun jika nilai signifikansi $F$ hitung $>0,05$ maka hal ini berarti pengaruh antara variabel bebas secara keseluruhan terhadap variabel terikat signifikan secara statistik. Berdasarkan Tabel, nilai signifikansi $F$ hitung adalah 
0,011. Karena nilai nilai signifikansi $F$ hitung lebih kecil dari 0,05 maka dapat disimpulkan bahwa Efikasi Diri dan Gaya Mengajar Guru secara simultan atau bersama-sama berpengaruh positif dan signifikan terhadap variabel Kedisiplinan Diri secara statistik.

Semakin tinggi tingkat Self Efficacy yang dimiliki oleh individu tentunya akan semakin tinggi pula kepercayaan atas kebolehan diri sendiri bahwa ia sanggup menggapai aktualisasi dirinya dengan usaha tindakan nyata dengan tidak mudah terhasut untuk melakukan hal-hal yang menyimpang dari norma-norma yang berlaku. Sebaliknya, jika Self Efficacy yang dimiliki individu rendah tentunya akan membuat individu tersebut mudah menyerah sebelum ada usaha dan tentunya akan gampang terhasut untuk melakukan hal-hal yang menyimpang hanya karena lebih mementingkan aktualisasi diri. Konsep self efficacy sebagai "kepercayaan mengenai kebolehan yang dimiliki individu guna memanajemen dan melaksanakan serangkaian aktivitas yang dibutuhkan dalam memperoleh harapan dan cita-citanya" (Pudjiastuti, 2012).

Adapun keterampilan menggunakan variasi adalah tindakan tenaga pendidik dalam hal tahapan kegiatan belajar mengajar peserta didik selalu memperhatikan sikap, keteguhan, bersemangat, dan terlibat secara aktif (Tahir \& Elihami, 2020). Dengan melakukan variasi dalam gaya mengajar, maka peserta didik tidak akan merasa bosan dalam proses pembelajaran. Guru yang melakukan improvisasi variasi gaya mengajar yang tepat tentu akan menarik perhatian siswa sehingga berimplikasi kepada peningkatan prestasi belajarnya. Seorang guru hendaknya berusaha agar variasi gaya mengajarnya dapat mendukung penjelasan yang disampaikan. Seorang pengajar perlu mempertimbangkan bahwa variasi gaya yang digunakan dalam mengajar merupakan tuntutan proses belajar mengajar yang ideal dan potensial dalam membentuk kerangka pikir logis bagi siswa.

Adanya variasi gaya mengajar yang baik dapat membantu siswa untuk lebih memfokuskan perhatian siswa pada pelajaran yang sedang diajarkan. Guru dapat menarik dan mempertahankan semangat belajar siswa, ketika guru memberikan variasi gaya megajar pada saat proses pembelajaran. Siswa akan terbantu untuk dapat meningkatkan dan mempertahankan kedisiplinan para peserta didik karena tidak merasa jenuh ketika terlibat dalam pelajaran dan dapat mengikuti pelajaran yang diberikan dengan baik. Penggunaan ragam gaya mengajar guru dapat mempermudah siswa mencapai kesuksesan sehingga secara tidak langsung, ragam gaya mengajar guru mempengaruhi tingkat prestasi belajar siswa. Dalam pembelajaran diharapkan guru juga dapat mengadakan variasi gaya mengajar, misalnya dengan memberikan berjalan mendekati siswa sambil memberikan penjelasan apabila siswa merasa kesulitan mengerjakan soal. Variasi gaya mengajar tersebut dapat diamati sebagai suatu energik, antusias, bergairah, dan memiliki relevansi dengan hasil belajar. Berdasrkan pemaparan teori tersebut maka dapat ditarik kesimpulan bahwasannya hasil penelitian sesuai dengan teori yang dikemukakan (Djamarah \& Zain, 2010).

Efikasi diri yang tinggi membuat siswa menyukai tugas-tugas yang menantang sehingga menimbulkan motivasi belajar yang tinggi pula untuk menyelesaikan tugas tersebut. Metode mengajar sebagai rangsangan dari luar memberikan pengaruh terhadap motivasi belajar siswa. Metode mengajar yang tepat dalam pembelajaran membuat motivasi belajar siswa tinggi, sebaliknya metode mengajar yang kurang tepat digunakan dalam pembelajaran membuat motivasi belajar siswa menjadi rendah. Begitupun penelitian yang dilakukan oleh Cahyani \& Winata (2020) hasil penelitian menunjukkan bahwa efikasi diri dan disiplin belajar memiliki pengaruh positif dan signifikan terhadap hasil belajar siswa, baik secara parsial maupun simultan. Oleh karena itu, hasil belajar dapat ditingkatkan melalui peningkatan efikasi diri dan disiplin belajar.

Seseorang dengan efikasi diri tinggi akan yakin bahwasannya ia sanggup dalam melaksanakan suatu hal guna merubah reihal yangada disekitarnya, sebaliknya apabila seseorang memiliki efikasi diri yang rendah maka ia akan berasumsi pada dirinya bahwa ia tidak sanggup untuk melakukan berbagai hal yang ada di lingkungan sekitarnya. Dalam keadaan yang kompleks,individu dengan efikasi diri yang rendah tentuhnya mudah putus asa. Sementara orang dengan efikasi diri yang tinggi senantiasa berupaya sedemikian rupa agar dapat menanggulangi persoalan yang ada (Fitriana et al., 2015). Disiplin belajar merupakan latihan menerima aturan-aturan, petunjuk bertingkah laku, larangan atau batasan yang harus dipatuhi dan keseimbangan antara kebutuhan serta tuntutan dari individu itu sendiri, hal itu 
semua melalui sosialisasi (Slameto, 2010). Sikap patuh dalam pembelajaran tentu semakin mempertajam ketangkasan dan kemampuan intelegensi terhadap intisari materi yang ditrasmisikan pada peserta didik, karena pada dasarnya peserta didik belajar sesuai dengan rasa sadar pada dirinya dan peserta didik senantiasa terdorong semangatnya untuk tetap belajar.

\section{Simpulan}

Tingkat efikasi diri Std. Deviation 16.33561 dan Asymp. Sign (2-tailed) 0,966\% peserta didik di SMA YPPK Taruna Dharma Kota Jayapura termasuk dalam kategori tinggi. Hal ini dibuktikan dengan ketika dilakukan penelitian lebih lanjut ketika cara mengajar Guru yang optimal, pada akhirnya efikasi diri pada siswa semakin tinggi dan membuktikan bahwa dalam pembelajaran, pengerjaan tugas serta kegiatan sehari-hari yang dilakukan siswa semakin meningkat dan sesuai dengan aturan yang berlaku. Tingkat gaya mengajar guru Dapat dilihat dari hasil analisis Std. Daviation 18.83250 dan Asymp. Sign. (2-tailed) 0,892\%, SMA YPPK Taruna Dharma termasuk dalam kategori baik. Hal ini dibuktikan dengan Fokus siswa dalam pembelajaran selaras dengan hasil yang dicapai. Tingkat kedisiplinan peserta didik Dengan hasil penelitian Std. Deviation 9.97613 dan Asymp. Sign. (2-tailed) 0,868\%. SMA YPPK Taruna Dharma termasuk dalam kategori baik. Hal ini dibuktikan dengan Semakin tingginya efikasi diri parapeserta didik didukung dengan cara pengajaran yang baik, maka kedisiplinan peserta didik pun meningkat.

Adanya hubungan yang positif dan signifikan antara efikasi diri dengan kedisiplinan peserta didik SMA YPPK Taruna Dharma. Adanya hubungan yang positif dan signifikan antara gaya mengajar guru dengan kedisiplinan peserta didik SMA YPPK Taruna Dharma. Adanya hubungan antara efikasi diri dan dengan kedisiplinan peserta didik di SMA YPPK Taruna Dharma Kota Jayapura.

Guru dapat menerapkan metode mengajar yang lebih baik dengan mempertimbangkan prinsip-prinsip pemilihan metode mengajar. Pemilihan metode mengajar yang tepat berpengaruh positif terhadap motivasi belajar siswa. Guru dapat memanfaatkan fasilitas yang ada di sekolah seperti laboratorium komputer, wifi, dan LCD untuk menerapkan metode mengajar yang mampu meningkatkan efikasi diri dan kedisiplinan peserta didik. Siswa dapat menghindari aktivitas mencontek saat ulangan/tes dengan meyakini kemampuan masinmasing. Efikasi diri yang tinggi akan berpengaruh positif terhadap kedisiplinan peserta didik.

\section{Ucapan Terima Kasih}

Terima kasih diucapkan kepada dosen pembimbing yang sudah mengarahkan, membimbing dan memberikan petunjuk, dan juga kepada pihak SMA YPPK Taruna Dharma Kota Jayapura yang secara sukarela dan menjadi tempat pelaksanaan penelitian.

\section{Daftar Rujukan}

Adestyani, E., Yusmansyah, Y., \& Widiastuti, R. (2020). Hubungan Antara Efikasi Diri Dengan Perilaku Plagiarisme Akademik Pada Siswa SMA. ALIBKIN (Jurnal Bimbingan Konseling), 8(2).

Al Khumaero, L., \& Arief, S. (2017). Pengaruh Gaya Mengajar Guru, Disiplin Belajar, Dan Teman Sebaya Terhadap Prestasi Belajar. Economic Education Analysis Journal, 6(3), 698-710.

Cahyani, N., \& Winata, H. (2020). Peran Efikasi dan Disiplin Diri Dalam Peningkatan Hasil Belajar Siswa. Jurnal Pendidikan Manajemen Perkantoran (JPManper), 5(2), 234-249.

Djamarah, S. B., \& Zain, A. (2010). Strategi Belajar-Mengajar (revisi). Jakarta: Rineka Cipta. 
Elly, R. (2016). Hubungan kedisiplinan terhadap hasil belajar siswa kelas $v$ di sd negeri 10 banda aceh. Jurnal Pesona Dasar, 3(4).

Fitriana, S., Ihsan, H., \& Annas, S. (2015). Pengaruh efikasi diri, aktivitas, kemandirian belajar dan kemampuan berpikir logis terhadap hasil belajar matematika pada siswa kelas VIII SMP. Journal of Educational Science and Technology (EST), 1(2), 86-101.

Nadhifa, F., Habsy, B. A., \& Ridjal, T. (2020). Konseling Kolompok Realita Untuk Meningkatkan Kedisiplinan Belajar Siswa Madrasah Ibtidaiyah Efektifikah? Perspektif IImu Pendidikan, 34(1), 49-58.

Pudjiastuti, E. (2012). Hubungan "self efficacy" dengan perilaku mencontek mahasiswa psikologi. MIMBAR: Jurnal Sosial Dan Pembangunan, 28(1), 103-111.

Slameto. (2010). Belajar dan Faktor-Faktor yang Mempengaruhinya. Rineka Cipta.

Sugiyono. (2010). Metode Penelitian Kuantitatif, Kualitatif, dan R\&D. CV Alfabeta.

Tahir, M., \& Elihami, E. (2020). PENINGKATAN VARIASI MENGAJAR PADA PROSES PEMBELAJARAN MAHASISWA SEMESTER TIGA DI PRODI PENDIDIKAN NONFORMAL STKIP MUHAMMADIYAH ENREKANG. JURNAL EDUKASI NONFORMAL, 1(1), 201-209.

Widiyaningtyas, E., \& Muhyadi, M. (2018). Pengaruh Efikasi Diri Siswa Dan Metode Mengajar Guru Terhadap Motivasi Belajar Siswa Kelas X Pada Mata Pelajaran Administrasi Umum Di SMK Abdi Negara Muntilan Tahun Ajaran 2017/2018. Jurnal Pendidikan Administrasi Perkantoran-S1, 7(4), 313-321.

\section{Competing interests:}

The authors declare that they have no significant competing financial, professional or personal interests that might have influenced the performance or presentation of the work described in this manuscript. 